\title{
MODELO DE INTEGRAÇÃO DE CONHECIMENTOS GEOLÓGICOS PARA AUXÍLIO À DECISÃO SOBRE USO DA TERRA EM ZONAS DE RECARGA DE AQÜÍFEROS
}

\author{
PAULO PEREIRA MARTINS JUNIOR ${ }^{1}$, ISSAMU ENDO ${ }^{1}$, JOÃO ÁLVARO CARNEIRO², \\ LEANDRO ARB D'ABREU NOVAES', MARCO AURÉLIO SEQUETTO PEREIRA ${ }^{3}$ \\ \& VITOR VIEIRA VASCONCELOS ${ }^{4}$
}

\begin{abstract}
Resumo: Geociências agrárias e ambientais (GAA) implicam em integrar diversas ciências e conhecimentos que subsidiem a prática da agricultura, silvicultura e zoocultura, de modo conservacionista, no âmbito da gestão de bacia hidrográfica. Uma das áreas protegidas por lei, mas comumente ocupadas, inclusive por desconhecimento de onde se situam nas muitas bacias, são as zonas de recarga de aqüíferos. São áreas sensíveis, nas quais uma simples proibição de atividades agrícolas pode não ser produtivo, visto que existem soluções ecológico-econômicas que seriam não somente viáveis quanto desejáveis. A integração de conhecimentos em Geologia estrutural, Hidrogeologia, Geomorfologia, Geotecnia, Pedologia, Aptidão de solos, Agronomia, Engenharia florestal, Lito-estratigrafia compõe um dos quadros de conhecimentos das GAA. Alguns aspectos da lógica de integração desses conhecimentos é aqui exposta de modo a se evidenciar esse novo ramo das Geociências. A Bacia do Rio Paracatu é alvo de estudo por ser uma região de frente agrícola intensiva. Os conceitos de segurança química, segurança do terreno e de uso agro-florestal intensivo e/ou orgânico compõem o quadro lógico para o auxílio à decisão na gestão de bacia. Decidir simplesmente com a aptidão de solos é limitado do ponto de vista geo-ambiental. Nesse trabalho, essa limitação é proposta a ser ultrapassada com um sistema de auxílio à decisão com uso de Inteligência artificial.
\end{abstract}

Palavras-chave: recarga de aqǘferos, segurança ambiental, ecologia-economia, geociências agrárias, inteligência artificial, tomada de decisão, sustentabilidade.

\begin{abstract}
AQUIFER RECHARGE ZONES AND ECOLOGIC-ECONOMIC CONSERVATIONAL SOLUTIONS WITH AGROFORESTRY PROJECTS - Agrarian Geosciences as a proposed new branch of knowledge implies the integration of various sciences, which serve to agriculture, forestry and animal breeding practices with conservation procedures for watersheds management. Underground water recharge zones are legally protected areas, but usually occupied for agricultural purposes given the general misinformation on their real localizations. They are sensible zones, where the very simple prohibition of agricultural activities may not be a productive approach meanwhile there are quite a good number of ecologic-economic solutions, which are viable and desirable. Knowledge procedures for integrating Structural Geology, Hydrogeology, Geomorphology, Geothenics, Pedology, Land sustainability, Litostratigraphy, Agronomy and Forestry engineering are parts of a knowledgeable approach to Agrarian Geosciences. A logical approach to integrate all this knowledge is presented in such a way that the Agrarian Geosciences may become evident to the reader. Paracatu watershed is the studied region with intensive agricultural projects. The concepts of chemical security, land sustainability, and the possibility of intensive agro-forestry projects as well as organic projects are part of a logic approach for helping decision making. To decide on the bases of soil sustainability, though absolutely correct from the agricultural point of view is a limited approach from a larger geo-environmental point of view. In this paper, these limitations are proposed to be partly overcome with artificial intelligent systems for supporting decision making.
\end{abstract}

Keywords: underground water recharge, environmental protection, ecology-economy, agrarian geosciences, artificial intelligence, decision making, sustainability.

INTRODUÇÃO O tema em proposição dá seqüência a estudos sobre fundamentação de um ramo das Geociências, então proposto como Geociências Agrárias e Ambientais GAA (Martins Jr., 1998). Entende-se que esse ramo se justifica pelo fato de não haver reflexão com práticas sistemáticas e integradas nas Geociências em interseção com a Agronomia, Engenharia florestal e Engenharia agrícola. Necessita-se articular para o fim proposto as seguintes disciplinas e temas: Epistemologia (Ep), Lito-estratigrafia (Le), Geologia estrutural (GE), Geomorfologia $(\mathrm{Gm})$, Climatologia $(\mathrm{Cl})$, Pedologia (Pd), Aptidão de solos (AS), Segurança ambiental (SA), Quimio-sensibilidade (Qs), Geotecnia (Gt) e Inteligência artificial (IA). Neste estudo, tratase de articular algumas bases cognitivas das Le, GE, AS e IA. No que diz respeito à IA, Laurière (1990) comenta que "todo o problema para o qual nenhuma solução algorítmica é conhecida, é um problema de IA". Assim no caso das GAA deve-se lançar mão das soluções de IA, quando se tem um trato interdisciplinar, para permitir decisões que são complexas, com múltiplas variáveis, afetando múltiplos sub-sistemas naturais e a viabilidade econômica de projetos agro-pastoris e florestais. A modelagem em IA é um método de grande importância para sistematizar qualquer esforço de integração operacional entre muitas ciências e muitos sistemas.

A área de estudo escolhida como referência para reflexão e exemplo é a bacia do rio Paracatu, situada no Noroeste de Minas Gerais e no Centro-Sul do Distrito Federal com área aproximada de 45.047,00 km² no Vale do Rio São Francisco (Fig. 1). A escolha da bacia se deve por tratar-se de um caso típico de área sub-

1 - (UFOP-EM-DEGEO Campus do Morro do Cruzeiro, 35.400-000 Ouro Preto, MG e Fundação CETEC, Av. J.C. da Silveira 2000, Horto 31.170-000, Belo Horizonte, MG paulo.martins@cetec.br) issamu@degeo.ufop.br)

2 - (CETEC, alvaro.carneiro@cetec.br) leandro.arb.@cetec.br)

3 - (CETEC idem, estag. UFMG-IGC marcosequetto@yahoo.com.br)

4 - (CETEC, idem, bolsista CNPq e FAPEMIG, Filosofia UFMG-FAFICH, vitor.vieira@cetec.br) Projeto CRHA - MCT / FINEP / Fundo Setorial CT-Hidro-2002 e Projeto ACEE (2003-2008) - CNPq convênio 507.379/20004-7. 
metida a imensos projetos de agricultura intensiva e haver problemas progressivamente crescentes com o uso consuntivo da água, erosão laminar e devastação do bioma dominante, o Cerrado.

Objetivos Alguns objetivos propostos para se responder à necessidade de modelar em IA podem ser classificados como objetivos de tipos: (1) descritivos, (2) lógicos e (3) de critérios de corte para a tomada de decisão. Agrupam-se em: (1) discutir em escala regional as implicações da inserção geológica das zonas de recarga de aqüíferos (ZRAs) e áreas precisas de recarga (APRs) no Vale, (2) apresentar critérios lógicos geo-ambientais, próprios para o auxílio à decisão, sobre usos agroflorestais da terra em ZRAs e APRs e (3) estabelecer algumas regras lógicas para gestão desses territórios com usos agroflorestais com a aplicação de projetos ecológico-econômicos que são definidos abaixo.

Problemas Os três objetivos estão conectados a um quadro de problemas que estão em foco nesse trabalho. Dos problemas possíveis para a gestão ambiental e a criação de um sistema de auxílio à decisão, destacam-se alguns que estão na raiz da construção das bases de informações para a construção de uma "Arquitetura de Conhecimentos para auxílio à decisão", a saber: (1) o que representam as estruturas rúpteis em relação às rochas portadoras de água subterrânea, juntamente com as propriedades físicas dessas rochas, como condições favoráveis, ou não, à percolação da água pluvial? (2) é possível se pensar o aproveitamento ecológico-econômico de quaisquer dos tipos de ZRAs, de tal modo que o uso econômico, com projetos agro-florestais, ou separadamente agrícola e florestal, permita ganhos sociais e, ao mesmo tempo, exerça função conservacionista? (3) como articular, regional e localmente, o auxílio à decisão com os atributos físicos de rochas e de formações superficiais que indiquem boas bases geotécnicas de viabilidade para esses projetos agroflorestais? (4) como articular, regional e localmente, o auxílio à decisão com os atributos físicos de rochas e de formações superficiais que indiquem más bases geotécnicas de viabilidade para que com esses projetos agro-florestais se possam articular soluções de mitigação? (5) em que medida esses atributos se superpõem a e/ou complementam as definições brasileiras de capacidade de uso e/ou de aptidão de solos? Por fim, (6) como estabelecer a conexão entre os vários temas de Ep, Le, GE, Gm, $\mathrm{Cl}, \mathrm{Pd}, \mathrm{AS}, \mathrm{SA}, \mathrm{Gt}$, o método CommonKads e IA com as condições sistêmicas do Vale, de modo articulado e integrado? Neste estudo dedica-se a Ep, GE, Le, AS, QS e as ZRAs.

A Recarga de Aqüíferos Convém adotar duas definições mais estritas para: (1) zonas de recarga de aqüíferos (ZRAs) como "todas as áreas em que ocorram infiltração em aqüíferos, agregadas geograficamente ou não, por tipos de rochas, condições geomórficas, pedológicas e/ou estruturais, reconhecíveis em escala regional" e (2) áreas precisas de recarga (APRs) como "áreas reconhecíveis em escala de detalhe em que ocorre a recarga em cada aqüífero específico, sendo áreas isoladas, ou não, dentro do contexto de uma ZRA".

Com essas duas definições, pode-se regionalmente trabalhar com os dados estratigráficos, geomorfológicos e as características físicas de solos em diferentes modos de articulação para a decisão regional e local. Sem dúvida o estado do intemperismo de rochas que permite a infiltração, ou não, nos poros e em profundidade é fator expressivo no processo, mas é aqui apenas citado como um aspecto que pode também ser considerado no modelo. Cabe ressaltar que no Vale do Paracatu existem áreas expressivas em que em uma mesma unidade lítica ocorrem recarga e descarga em função de vários aspectos estruturais, estratigráficos, do relevo, das características das rochas e do grau de intemperismo.
MÉTODOS Esse estudo faz parte de um esforço para trazer as Geociências e as GAA em contexto com as outras ciências de interesse para a gestão ambiental e agrícola. O método aqui seguido é denominado de Arquitetura ou Engenharia de Conhecimentos (Schreiber et al., 2000) e nesse texto utiliza-se a forma Arquitetura, pelo fato de que ao fim todas as implicações lógicas entre as ciências especialistas, os sistemas naturais com elas estudados e as atividades agrícolas, florestais e pastoris devam ser integrados de modo a permitir decisões de gestão geo-ecológica e agrícola. Alguns princípios sobre o viés ecológico-econômico para a viabilidade de projetos são desenvolvidos nesse texto, de modo adicional.

Três métodos específicos se encadeiam como uma exigência contextual (Martins Jr, 2002): (1) uma análise epistemológica (Epistemologia como Teoria do conhecimento) para articular justificadamente conhecimentos científicos de bases diversas entre si, e que deve ser desenvolvida com o apoio dos seguintes Sistemas de Inquirição (SI) (Martins, Jr. 2002): (a) o SI Kantiano, que permite integrar "a verdade das bases de dados", ao molde conceitual do SI Lockeano, à "verdade da teoria" ao molde conceitual do SI Leibniziano (b) o SI Hegeliano que permite, com a dialética, tratar com teses e antíteses, tão úteis para lidar com a gestão de conflitos de interesse, ainda que se realize a gestão dentro das regras das leis e das normas técnicas da produção agrícola e (c) o SI Singeriano-Churchmaniano que permite lidar com a deriva do conceito de verdade de um modo temporal pragmático em face à complexidade de situações e objetivos, quando, com decisões a serem tomadas em face de riscos e de mudanças de técnicas, necessite-se criar ou se configurem novos cenários. Assim se podem viabilizar possibilidades, antes não possíveis, de sustentabilidade ambiental e econômica, ante o quadro de novas técnicas; (2) o método CommonKads (Schreiber et al., 2000) para lidar com todas as implicações dos relacionamentos funcionais de um programa especialista com os sistemas de inquirição, as ciências especialistas com as situações geo-ambientais e (3) a linguagem UML (Unified Modeling Language), internacionalmente adotada, para estruturar a programação de sistemas especialistas. O método CommonKads com a linguagem UML, que é uma linguagem gráfica padrão para a elaboração da estrutura de projetos complexos de programação, devem ser empregados para visualizar, especificar, construir e documentar os artefatos de sistemas de programação (Booch et al.,1999).

Neste texto, usa-se principalmente o método da Análise epistemológica conjugado com a Análise geológica, como primeiro passo de montagem de uma Arquitetura de Conhecimentos. Alguns resultados lógicos foram desenvolvidos com os procedimentos do método CommonKads e são discutidos para fechar em nível mais alto de contexto o campo lógico mínimo de questões, e modos de solucioná-las. Alguma modelagem em UML (fig.11) é apresentada em nível também de contexto, já que essa antecede à subseqüente fase de implementação em linguagem fonte, após ter-se explorado ao máximo toda a organização lógica interdisciplinar com o método CommonKads.

Cartas geológicas como fontes de informação A carta litoestratigráfica (CETEC, 1981), atualizada em 2005 no Projeto CRHA, foi integrada a vários estudos estruturais (Endo et al., 2006) (Martins Jr., et al., 2005 A e B) realizados com a cartografia regional das estruturas rúpteis. Produziu-se novas cartas com as densidades espaciais dessas mesmas estruturas, medidas por unidades de área (Fig.1 e Figs. 3a a 7b). Estão disponíveis em cartas de densidade geradas para cada unidade estratigráfica, com destaque para as três curvas de mais altas densidades. Tal distribuição permite ver, acima, na página anterior, a variação de densidades no espaço em relação aos sistemas de 


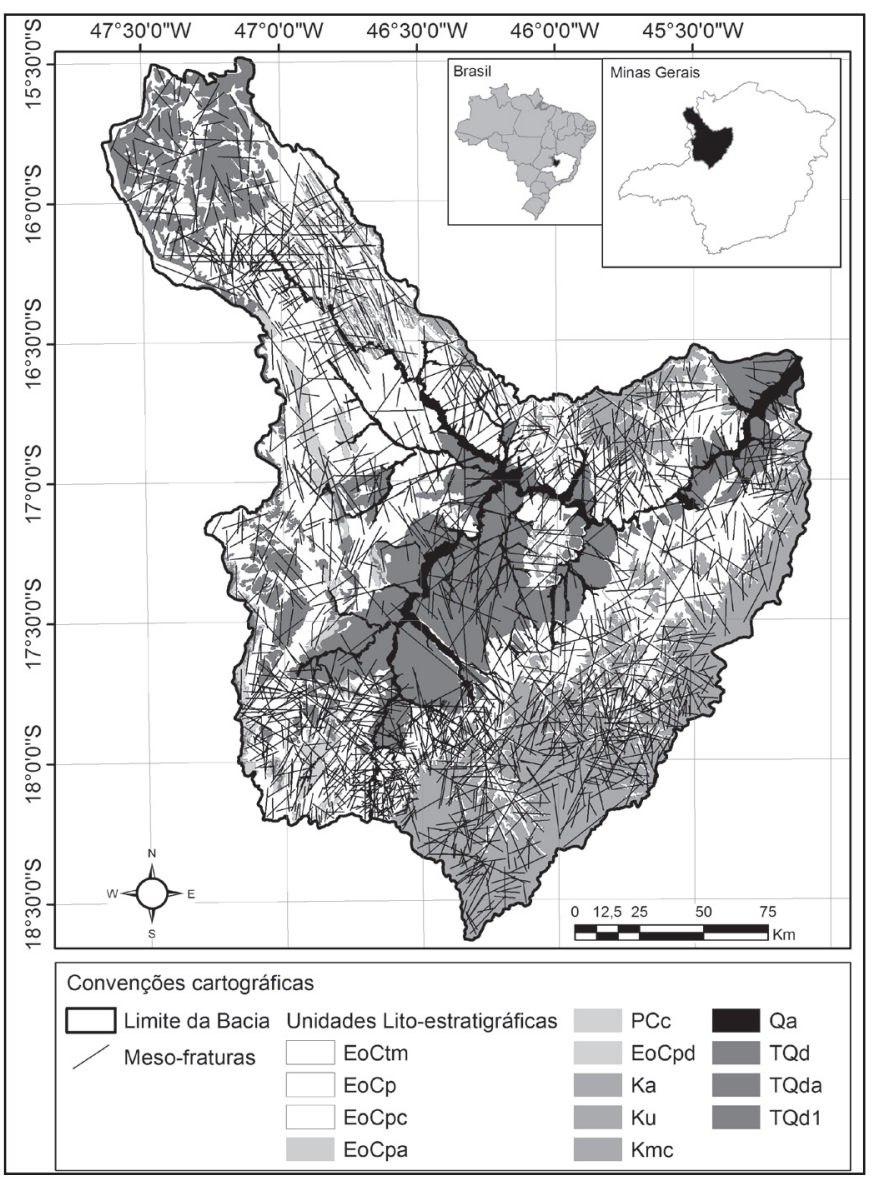

Figura 1 - Sobre base estratigráfica CETEC (1981) apresentase o mapeamento das estruturas rúpteis na bacia hidrográfica do Paracatu (Projeto CRHA 2003-2006). Simbolos reportam-se à Tabela (escala original 1:250.000).

rochas na escala original de 1:250.000. Em suma, busca-se com este procedimento estabelecer relações entre estruturas rúpteis, ocorrências de fontes quanto às suas localizações e quantidades com: (1) encaixes de cursos d'água, (2) zonas e áreas precisas de recarga identificadas ou inferidas nos limites do método e da escala e (3) as condições de infiltração e de exsudação, que são elementos territoriais de informação para acesso pelo sistema especialista.

As unidades líticas da Figura 1 e Tabela 1 devem ser consideradas no seu todo como unidades aqüíferas com ZRAs, reservatórios, e/ou também com zonas de transição e os conjuntos de fontes, para em escalas mais adequadas serem mapeadas as APRs com os reservatórios.

Já os sistemas de aqüíferos são apresentados na Figura 2 e Tabela 2 .

CIRCULAÇÃO PROFUNDA EM RELAÇÃO COM AS ESTRUTURAS RÚPTEIS E A GEODINÂMICA EXTERNA Embora o foco do assunto não seja a discussão da Geologia estrutural, enquanto tal, aponta-se a partir dessa para a Arquitetura de Conhecimentos de modo a permitir vir-se a tratar o conhecimento estrutural por um sistema especialista de auxílio à decisão. A análise de mapas estruturais rúpteis da bacia do Paracatu visa subsidiar considerações sobre a geodinâmica externa em relação ao interesse de se detectar ZRAs e diversas outras indicações sobre as condições de circulação hídrica, bem como de se estabelecer critérios importantes para o auxílio a decisão sobre os usos da terra.
Tabela 1 - Estratigrafia da Bacia sedimentar de São Francisco no Vale do Paracatu apresentada na Figura 1 (CETEC 1981).

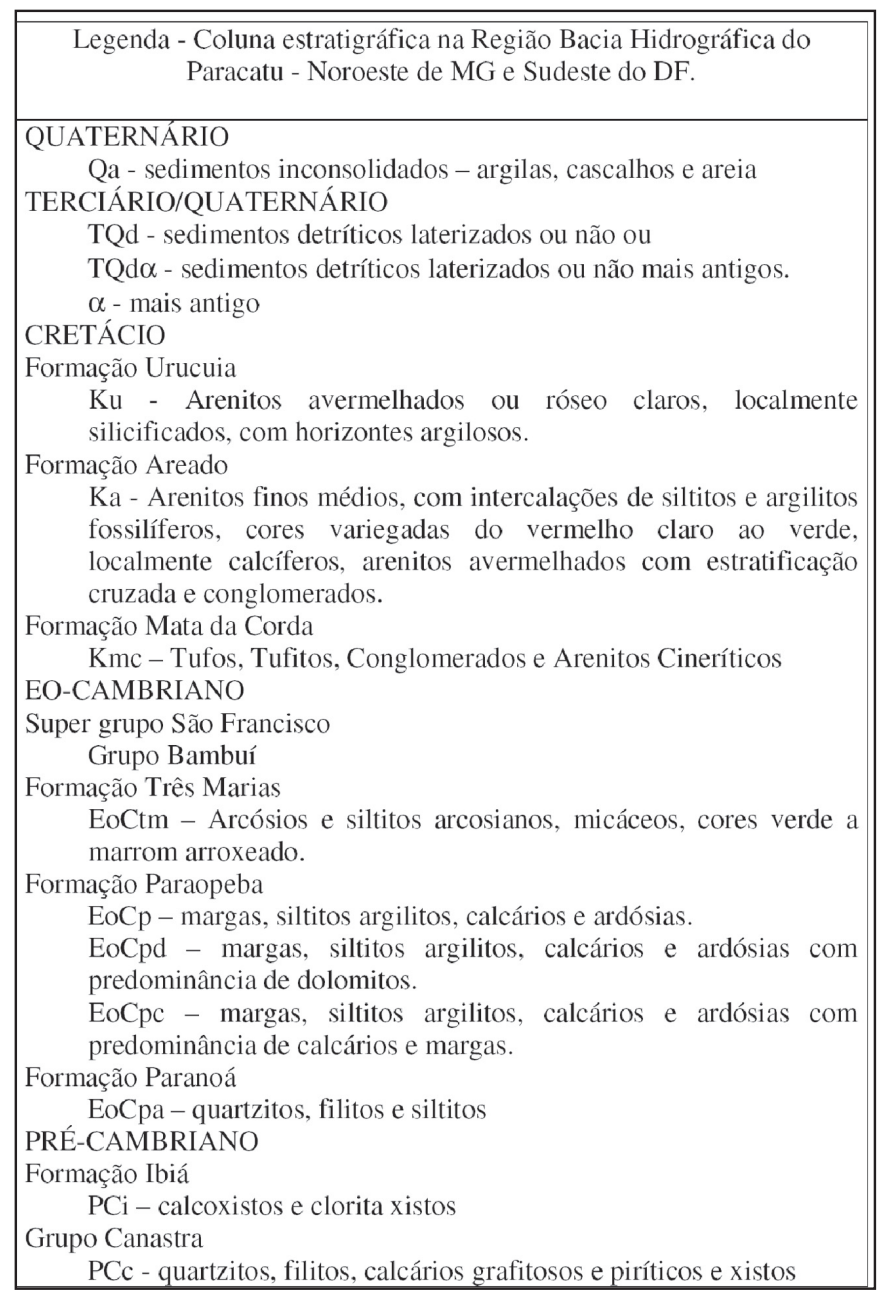

Sobre a localização de aqüíferos e de suas captações A localização é resultado de um conjunto de fatores, que se combinam de modos os mais diversos. Os fatores lito-estratigráficos podem ter como singular aspecto, a possibilidade de estratificação de mais de um aqüífero em duas rochas distintas, localmente superpostas ou com localizações latero-verticais. Pode ser um fato raro, talvez, mas não impossível, especialmente se as rochas portadoras subjacentes estiverem confinadas. Eventualmente, um sistema de fraturas em um evento tectônico pode afetar identicamente duas rochas superpostas e o aqüífero possa, assim, pertencer às duas ao mesmo tempo, com diferentes situações: (1) as duas rochas são portadoras, embora uma seja a receptora e por circunstâncias estruturais a receptora possa ser a rocha sobrejacente (2) a rocha sobrejacente pode ser unicamente captadora e reservatório (3) ambas as rochas podem ser captadoras e contenedoras, embora estratigraficamente superpostas, mas os dois aqüíferos independentes e (4) as captações podem ser intercomunicadas e/ou estarem separadas em duas áreas distintas.

O estudo da distribuição de fraturas por unidade geológica (Figs. 3a a 7b) é feito de modo que cada mesofratura, assim denominadas segundo Blanchet (1956) e Mollard (1957), ou às vezes as falhas e as fraturas de grande extensão, só sejam contabilizadas quando pertencentes a uma única unidade geológica, ou de outro modo a mais de duas unidades (Silva et al., 1989). Existem problemas quanto a certeza de uma estrutura rúptil pertencer a uma única unidade lítica, ou a mais de uma. Quando uma estrutura rúptil cruza duas unidades pertence ne- 


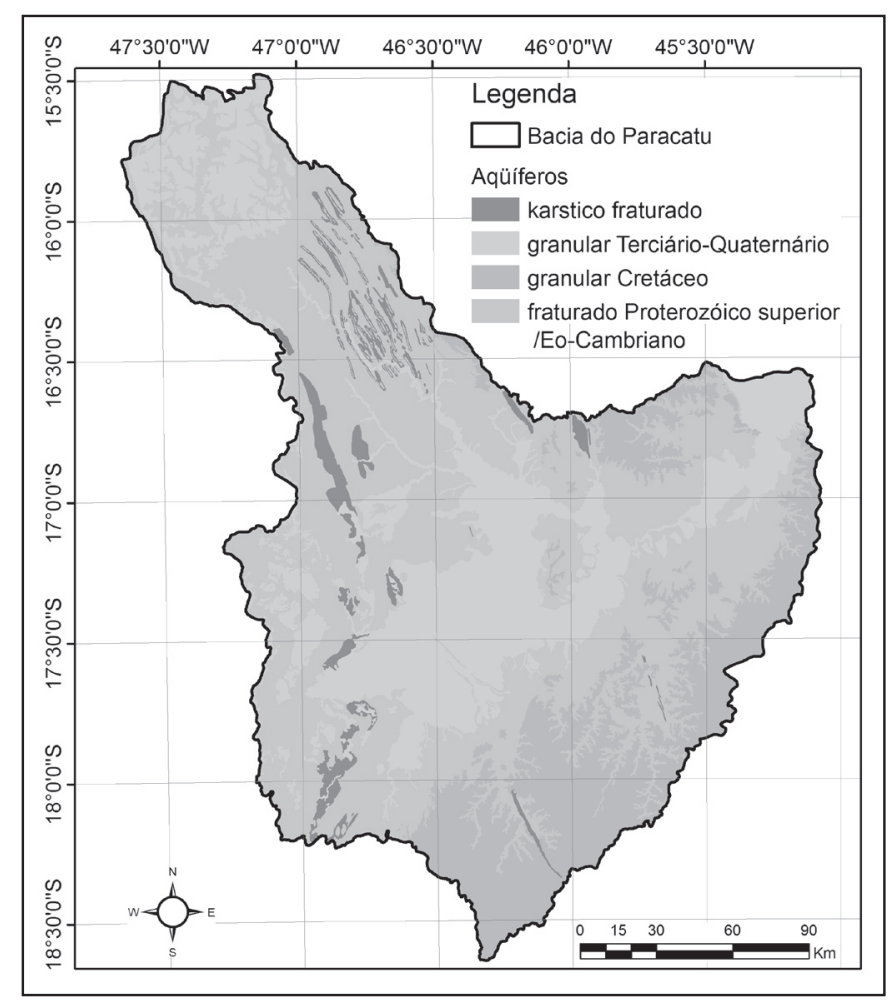

Figura 2 - Mapa das superficies de inserção dos aqüiferos subterrâneos da Bacia do Rio Paracatu; essas são superficies que incluem áreas não-aqüiferas propriamente ditas, zonas de recarga dos aqüiferos, áreas correspondentes aos reservatórios e áreas de exsudação; outras áreas são as de afloramentos de aqüiferos superficiais como veredas, áreas de inundação, de lagoas permanentes e temporárias (escala original 1:250.000).

cessariamente às essas duas. Isto que é óbvio, a primeira vista tem, todavia, em outras situações algumas implicações distintas. Assim vejamos: [1] quando "só" cruzarem uma única unidade, de modo visível, isto pode significar que pertençam tão somente a essa uma unidade geológica, mas nada impede, todavia, que pertençam também a uma outra unidade subjacente, o que pode ser possível, ainda que não visível em superfície [2] quando estruturas rúpteis cruzarem duas unidades geológicas não superpostas implica que, necessariamente, são mais novas que a unidade mais nova, ou são rejuvenescimento de uma estrutura mais antiga com uma expressão sobre a unidade mais nova e [3] quando cruzarem uma unidade mais antiga, e não cruzarem nenhuma unidade mais nova implica, em princípio, terem sido formadas em tempos anteriores à formação das unidades mais novas sobrejacentes. Isto não é ainda, todavia, fato absoluto dado que podem pertencer a um mesmo evento que atuou sobre as duas unidades, e que não deixou expressões distribuídas por igual nessas duas unidades, ou que mesmo, possivelmente, partes do terreno, que igualmente tinham estruturas rúpteis partilhadas, não mais as tenham por terem sido "apagadas pelo efeito da erosão" de amplas extensões de uma das duas unidades líticas, em especial da unidade mais alta estratigraficamente. Em todos os sentidos que interessam ao tema, as estruturas rúpteis podem ser, e o são muitas vezes, caminhos possíveis para circulação profunda da água nessas variadas situações geo-ambientais. Isto é notável nesse Vale. A importância do assunto diz respeito a partilha de água entre aqüíferos e a eventualmente penetração de substâncias químicas nos aqüíferos.

Direções das fraturas As fraturas, falhas e as mesofratu- ras (fraturas de tamanhos médios em uma região) apresentam um quadro próprio nas diversas áreas e na totalidade da bacia. Quando se separam áreas da bacia do Paracatu nas quais existam ocorrências expressivas de corpos d'água como veredas, lagoas permanentes e lagoas temporárias, áreas pantanosas e de inundação, as áreas de máximos de fraturamentos e de máximos de nascentes colocam uma questão sobre as relações dessas estruturas com a existência de corpos d'água dos mais variados tipos no espaço dessa bacia.

Observa-se que existe uma melhor caracterização entre as estruturas rúpteis das formações EoCp e TQd-Qa do que entre as unidades EoCp e EoCtm, no que diz respeito a densidades de direções. Em todas essas situações as direções NO-SE são marcantes, ainda EO e também NE-SO a $\approx 45^{\circ}$. As direções NE-SO entre $0^{\circ}$ e $30^{\circ}$ são também notáveis. No conjunto as três unidades líticas parecem seguir padrão comum (Fig. 8a a 8d), com algumas poucas diferenças.

Importantes aspectos podem ser ressaltados ainda quando se identificam as idades relativas das mesofraturas no Paracatu, por serem lugares prováveis de infiltração e/ou de circulação entre aqüíferos. Assim, nesse contexto, coloca-se outra questão: - as áreas de maiores densidades de fraturas têm maior relação com as áreas precisas de recarga ou com as áreas de exsudação? Em realidade a situação indica ser complexa no Paracatu, inclusive com áreas de comum infiltração e exsudação, em contraste com aquelas áreas que seriam unicamente de infiltração, e outras exclusivas de exsudação. É necessário resolver com observações mais específicas de detalhe, mas em certos casos fica evidente o caso duplo - infiltração e exsudação.

As conclusões não são ainda definitivas para todas as áreas e, tampouco, foram totalmente idênticas àquelas sobre as localizações das ZRAs, como sugeridas no Plano Diretor (Consórcio Magna/Dam/Eyser, Ruralminas, SEAPA-MG. 1998). As ZRAs estão mais provavelmente em áreas de menor densidade de fraturas (Fig. 9) salvo as exceções dos aqüíferos fraturados. De outro modo indiferentemente da existência de fraturas as ZRAs são comuns e extensivas em áreas tabulares com aqüíferos granulares, mas também com relativa importância em áreas mais restritas do karst fraturado da Fm. Paraopeba (Fig. 2). Todavia as APRs e as áreas de exsudação estão certamente entremeadas em algumas ZRAs, e também em áreas que não se constituem em aqüíferos típicos como as formações TQd e Qa.

Zonas de recarga de aquíferos As ZRAs fazem, no Vale do Paracatu, parte de um complexo sistema de circulação da água, que envolve: (1) ZRAs isoladas (2) áreas de transmissão que funcionam como ZRAs, embora sejam áreas apenas de transmissão da água, sem que se constituam necessariamente como aqüífero, com reservatório (3) as ZRAs que devem se situar, maiormente, fora das áreas de máximos de nascentes e de fraturas, ressalvadas algumas possíveis localizações em aqüíferos fraturados (Grupo Canastra, Fms. Paranoá e Três Marias) e também no karst fraturado (Fm. Paraopeba) (4) as ZRAs que se situam em conjugado com as áreas de exsudação e (5) as ZRAs que estão estratificadas com comunicação via estruturas rúpteis, ou mesmo sem comunicação por essa via.

As ZRAs no Vale do Paracatu Essas áreas são diversas em tipo geológico, quanto as localizações, condições ambientais naturais ou condições de impactos antrópicos já existentes, como também em sensibilidade geotécnica sob os aspectos estruturalmecânico e quimio-sensível. Por outro lado, algumas áreas têm a característica de serem ambivalentes em termos de recarga e de exsudação, servindo como meio de transmissão sem que se possam caracterizar reservatórios típicos de aqǘf́ros.

Os terrenos TQd, TQda e TQd1 (Figura 7b) têm como ca- 
Tabela 2 - Sistemas Aqüiferos da Bacia do Rio Paracatu (Consórcio Magna / Dam/Eyser, Ruralminas, SEAPA-MG. 1998).

\begin{tabular}{|c|c|}
\hline Sistemas Aqüíferos & Litossomas Predominantes / Unidades Geológicas Associadas \\
\hline MEIO GRANULAR & ocorrência de 41,3 \% da área total da bacia. \\
\hline $\begin{array}{l}\text { Aqüíferos Quaternários } \\
{[5,4 \%]}\end{array}$ & depósitos aluviais (Qa) - areias, siltes, argilas e cascalhos. \\
\hline Aqüíferos Terciário/Quaternários & coluviões e coberturas detríticas - TQd - areias finas a médias \\
\hline$[25,9 \%]$ & com argilas, às vezes lateritizadas, e cascalheiras (TQd $\alpha$ ) \\
\hline $\begin{array}{l}\text { Aqüíferos Cretácicos } \\
{[10,0 \%]}\end{array}$ & $\begin{array}{l}\text { Fm. Mata da Corda - Kmc; Fm. Urucuia - Ku; e Fm. Areado - Ka: arenitos } \\
\text { predominantemente finos; secundariamente conglomerados; argilitos e siltitos } \\
\text { intercalados e tufitos }(\mathrm{K}) \text {. }\end{array}$ \\
\hline \multicolumn{2}{|l|}{ MEIO KÁRSTICO } \\
\hline $\begin{array}{l}\text { Aqüíferos kársticos } \\
{[6,7 \%]}\end{array}$ & $\begin{array}{l}\text { Fm. Paraopeba EoCpd, do Gp. Bambuí - facies carbonatada, calcários e } \\
\text { dolomitos, com intercalações argilosas. }\end{array}$ \\
\hline \multicolumn{2}{|l|}{ MEIO KÁRSTICO-FRATURADO } \\
\hline $\begin{array}{l}\text { Aqüíferos kárstico-fraturados } \\
{[33,6 \%]}\end{array}$ & $\begin{array}{l}\text { Fm. Paraopeba EoCpc do Gp. Bambuí - facies argilo-carbonatada a pelítica } \\
\text { (ardósias, meta-argilitos, meta-siltitos e margas, com intercalações de rochas } \\
\text { carbonáticas). }\end{array}$ \\
\hline \multicolumn{2}{|l|}{ MEIO FRATURADO } \\
\hline $\begin{array}{l}\text { Aqüíferos fraturados } \\
{[18,4 \%]}\end{array}$ & $\begin{array}{l}\text { rochas do Gp. Canastra - quartzitos e xistos } \\
\text { Fm. Paranoá EoCpa (filitos e quartzitos grosseiros inter-estratificados); Fm Três } \\
\text { Marias EoCtm (arcósios predominantemente). }\end{array}$ \\
\hline
\end{tabular}

racterísticas serem meios de transmissão nos quais a chuva penetra, atravessa e sai diretamente em um número de fontes em torno. São rochas granulares particularmente quimio-sensíveis com solos de vários tipos. Os terrenos kársticos oferecem condições típicas, sendo que se dividem em dois tipos o kárstico e o kárstico fraturado, como se destacam na figura $3 \mathrm{a}$ e $3 \mathrm{~b}(\mathrm{Fm}$. Paraopeba). Os aqüíferos nas rochas cretácicas são granulares típicos e formam lençóis sendo, por isso, extensos e comunicáveis, possivelmente, por diferentes estruturas rúpteis partilhadas com as rochas do Grupo Canastra. Esses aqüíferos, também afetados pelo sistema rúptil, e que são mais altos estratigráfica e topograficamente podem se comunicar com os aqüíferos fraturados $\mathrm{Ca}$ nastra de quartzitos, xistos e arcósios fortemente afetados pelo sistema rúptil.

Em realidade, foram montados todos os mapas de densidades de fraturas, por unidade geológica e pela totalidade da grande bacia (Figs. 3 a 7), e as representações das Figs. 9 e 10 fornecem uma visão integrada de zonas importantes de distribuição dessas fraturas e, portanto, de zonas de exsudação, bem como em alguns casos, também, de zonas de infiltração.

Outros fatores devem ser considerados para cada área de densidades máximas, em se tratando de relações geo-ambientais versus projetos agro-florestais. A cada situação e a cada tipo de projeto as relações emergem em função dos conhecimentos, de fato existentes, para uma dada área geo-ambiental, em especial as relações sobre essas estruturas como áreas de possível infiltração e a necessidade de se implementar projetos agrícolas com uso de insumos químicos.
LÓGICA DAS GEOCIÊNCIAS AGRÁRIAS E AMBIENTAIS PARA A ARQUITETURA DE CONHECIMENTOS A questão central do uso agroflorestal de ZRAs e APRs diz respeito a três fatores objetivos para o auxílio à decisão, a saber:"o que plantar", "onde plantar" e "como plantar". A questão "o que" implica em lidar com as GAA e com as outras ciências citadas acima, bem como com a noção de viabilidade em diversos níveis agro-silvi-climatológicos, de aptidão de solos e de maior ou menor investimento em técnicas. "Onde plantar", neste caso, já é um pressuposto da questão em estudo ser em ZRAs e em APRs, todavia onde ainda implica o estudo caso a caso, a ser levado a sério um processo de gestão de necessário licenciamento, ainda que não exista esta prática no País, pelo menos ao modo como aqui se discute. O "como plantar" já implica nas seguintes situações: (1) a aptidão de solos com as condições apto, restrito e inapto, que envolvem técnicas diferentes quando a decisão for pelo "sim"; (2) as condições geotécnicas que, em face das variáveis de estabilidade de terreno, envolvem técnicas distintas quando a decisão for pelo "sim", quaisquer que sejam os graus de sensibilidade do terreno; (3) as opções agricultura e silvicultura que envolvem questões técnicas diversas para os dois tipos de sistemas produtivos; (4) quando for projeto integrado agroflorestal a necessidade de um zoneamento conveniente das ZRAs e APRs e (5) os cuidados extremos que se devem tomar para que em nenhuma hipótese a recarga em si seja comprometida, em especial pela diminuição da infiltração em relação ao escoamento superficial imediato pós-chuvas.

Em todas as considerações acima está em foco, como premissa, a questão da estabilidade do terreno em relação com a 

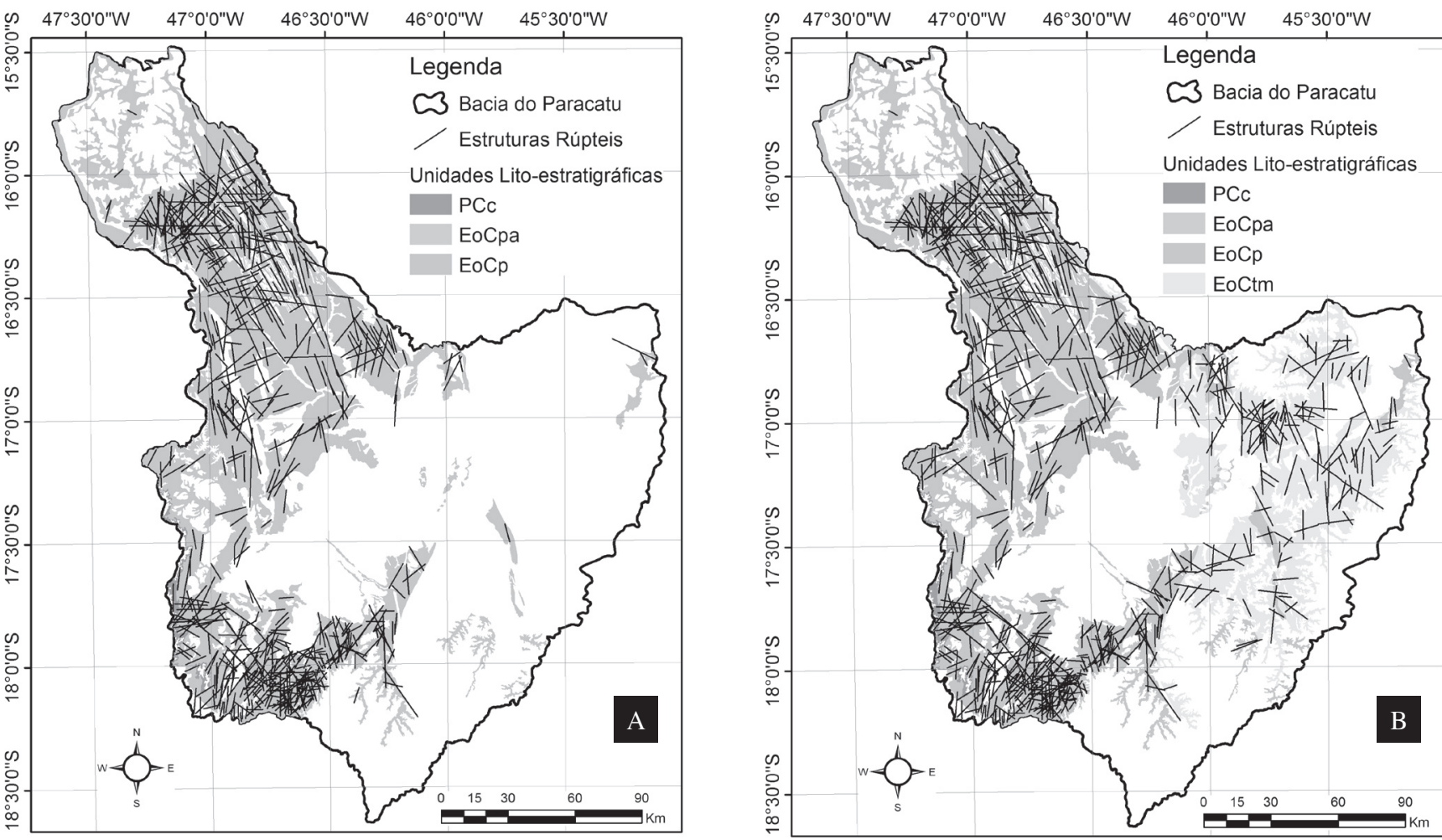

Figura 3 a - Carta de fraturas referentes a evento tectônico que afetou as unidades PCc Grupo Canastra, EoCpa Formação Paranoá e EoCp Formação Paraopeba composta de margas, siltitos argilitos, calcários e ardósias. A parte do território a noroeste, no Distrito Federal, não foi mapeada para essas estruturas. Figura $3 b$-Carta de fraturas referentes a evento tectônico que afetou as unidades PCc Grupo Canastra, EoCpa Formação Paranoá, EoCp Formação Paraopeba composta de margas, siltitos argilitos, calcários e ardósias e EoCtm Formação Três Marias arcósios e siltitos arcosianos, micáceos, cores verde a marrom arroxeado.
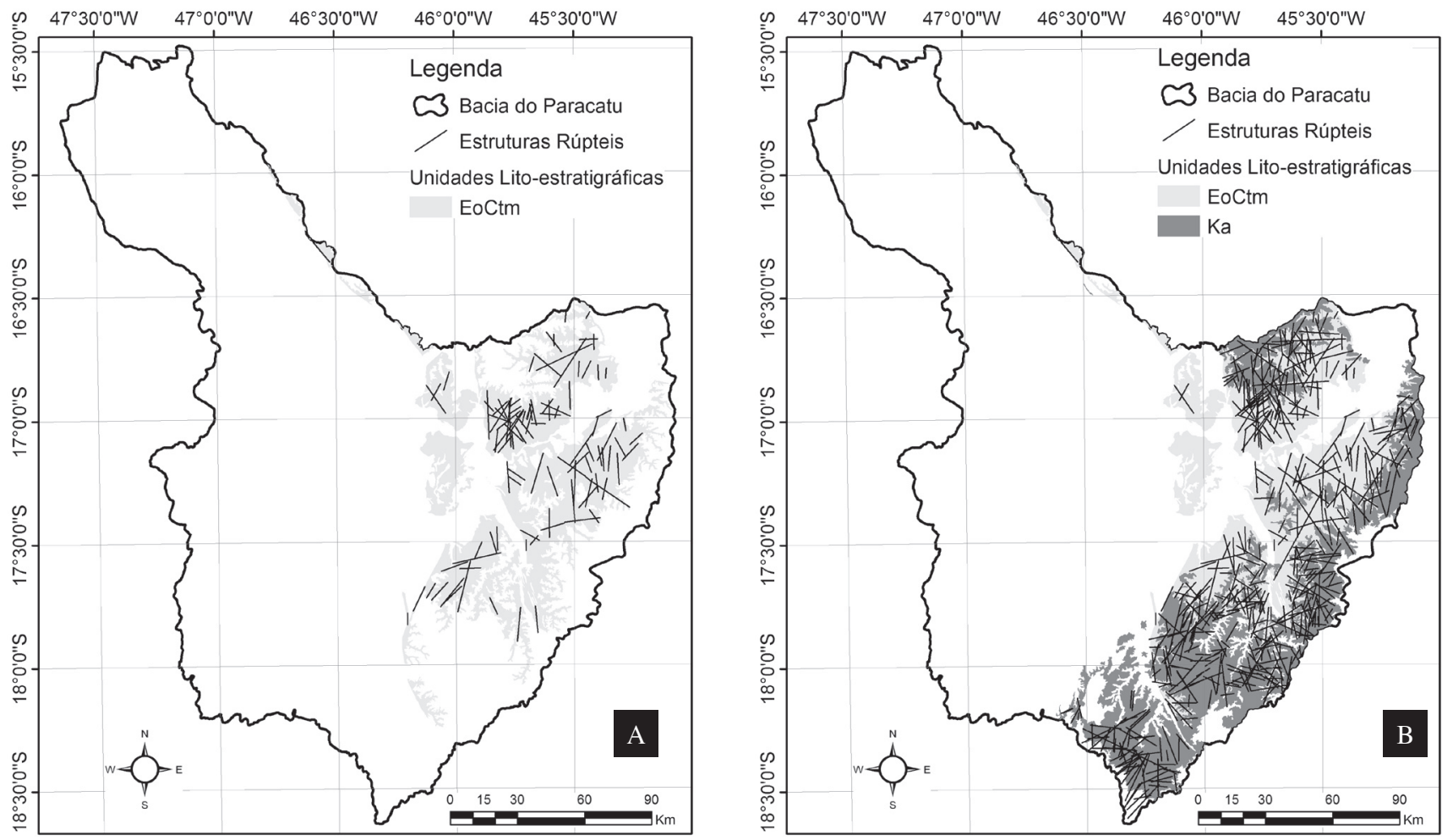

Figura 4 a - Carta de fraturas referentes a evento tectônico que afetou as unidade EoCtm Formação Três Marias EoCtm - arcósios e siltitos arcosianos micáceos, cores verde a marrom arroxeado; $4 b$ - Carta de fraturas referentes a evento tectônico que afetou as unidades EoCtm Formação Três Marias - arcósios e siltitos arcosianos micáceos, cores verde a marrom arroxeado e a Formação Areado Ka. 

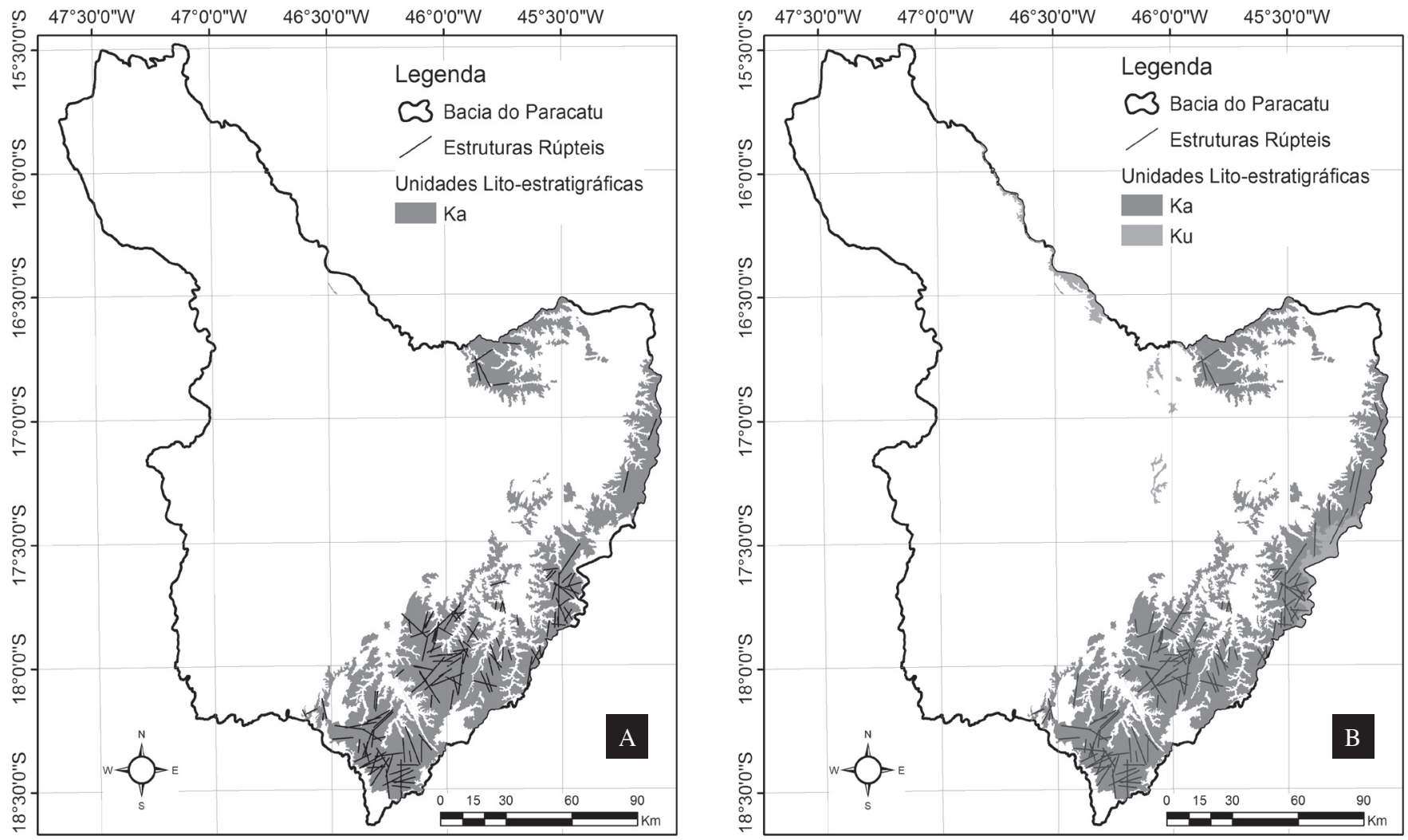

Figura 5 a - Carta de fraturas referentes a evento tectônico que afetou a unidade Ka Formação Areado. $5 b$ - Carta de fraturas referentes a evento tectônico que afetou as unidades Ka Formação Areado e Ku Formação Urucuia. A Formação Urucuia não tem indicações de estruturas rúpteis por não detecção na Bacia do Paracatu onde é de pequena expressão.
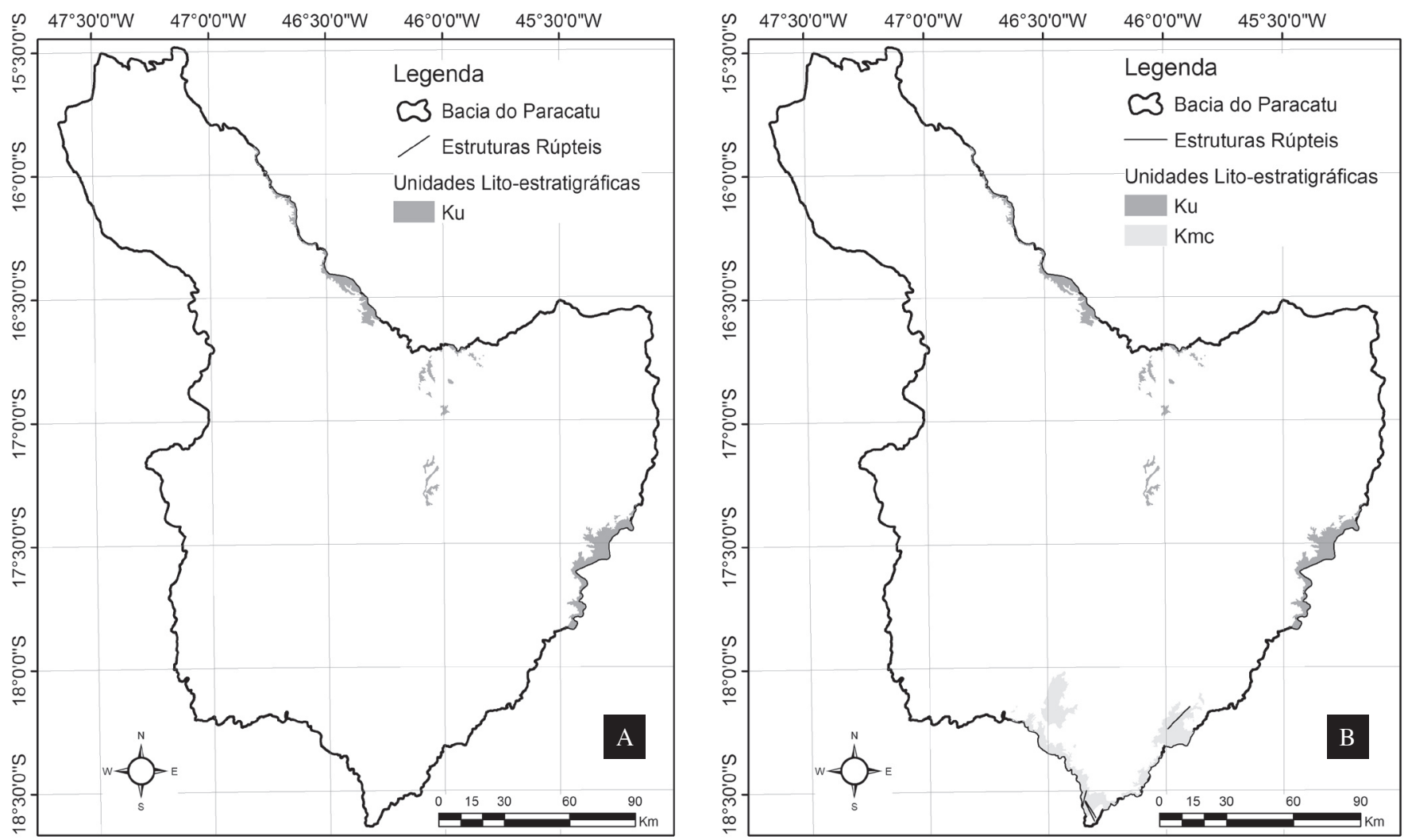

Figura $6 a$ - Carta de fraturas referentes a evento tectônico que afetou as unidades Ku Formação Urucuia e Kmc Formação Mata da Corda - tufos, tufitos, conglomerados e arenitos cineríticos. 6 b - Kmc Formação Mata da Corda - tufos, tufitos, conglomerados e arenitos cineríticos sem indicação de estruturas rúpteis por falta das mesmas nesta parte da Bacia do Paracatu. 

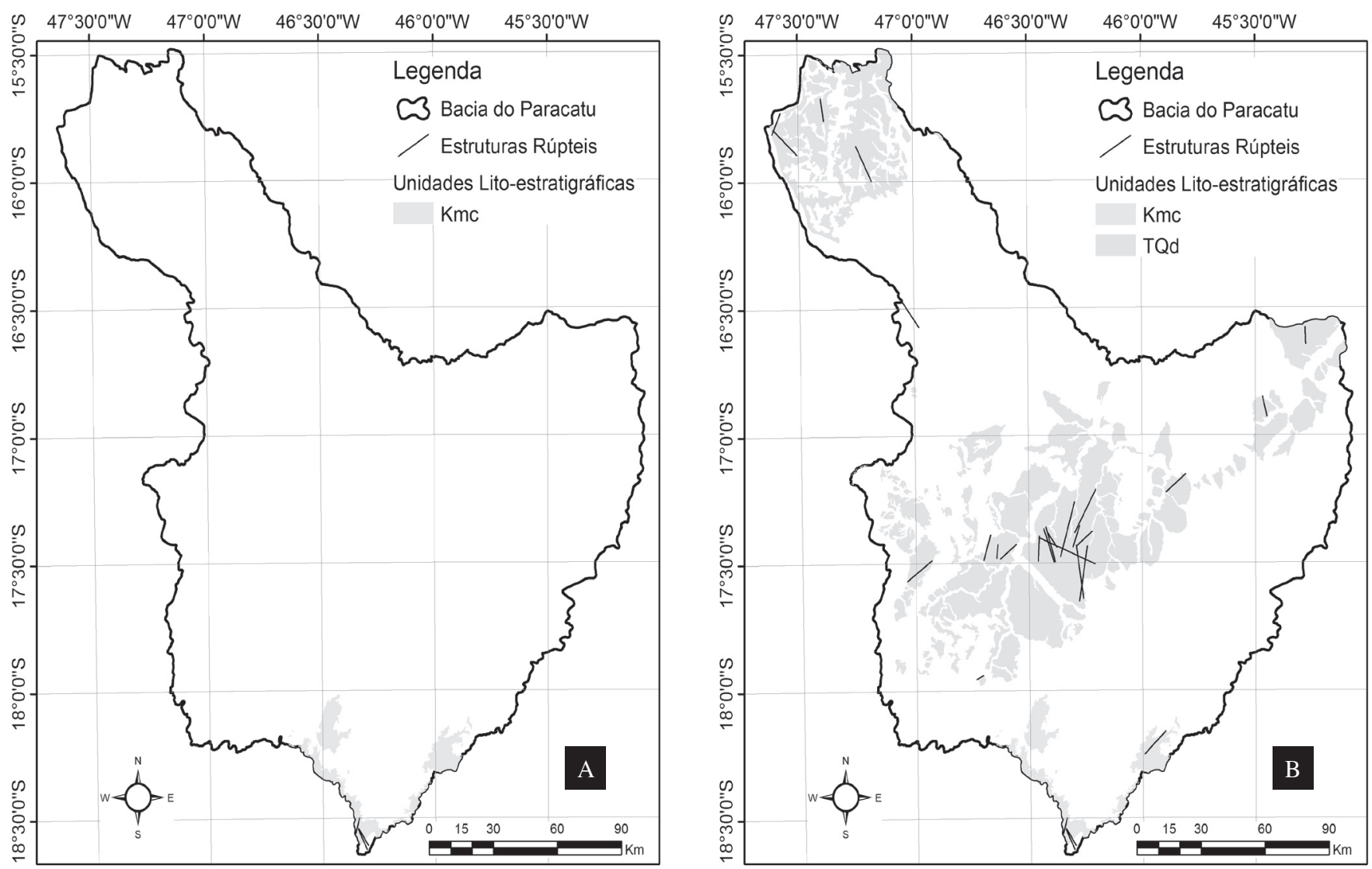

Figura $7 a$ - Carta de fraturas referentes a evento tectônico que afetou a unidade TQd-sedimentos detríticos laterizados ou não. $7 b$ - Carta de fraturas referentes a evento tectônico que afetou a unidade Qa do Quaternário.

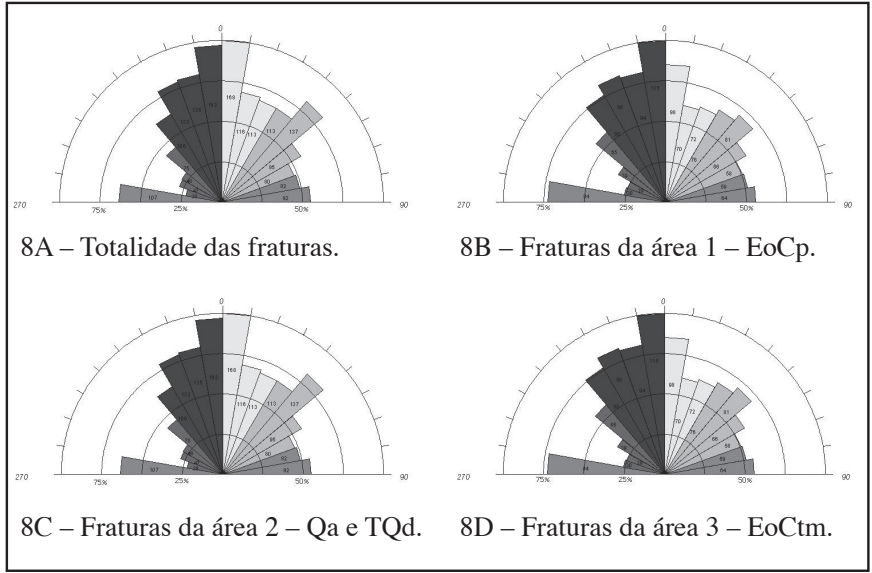

Figura $8 A$ a $8 D$ - Rosetas de freqüências das direções de fraturas nas Figuras $6 A$ a $6 D$.

viabilidade agroflorestal, a manutenção dos ecossistemas bem como das recargas. Resta por fim a questão da segurança química das ZRAs e APRs, que implica na análise das características geotécnicas específicas dos solos locais e das condições de pluviosidade, bem como a condição de ambientes naturalmente mais úmidos e de sequeiro dentro de ZRAs dados os vários tipos de culturas. Esses fatores devem ser contingenciados ao aspecto crítico da permeabilidade dos solos e as áreas de infiltração.

As Geociências devem subsidiar a Arquitetura de Conhecimentos com os seguintes temas: (1) estruturas rúpteis em localização, quantidade e relação com as rochas (2) importância das estruturas rúpteis como eventuais e/ou efetivos meios de infiltração entre unidades líticas (3) os solos e suas respectivas capacidade de campo (4) as declividades e geoformas associadas a rochas e solos (5) as áreas de máximas densidades de mesofraturas (6) as direções preferenciais das estruturas rúpteis em relação com as fontes (7) as direções preferenciais das estruturas rúpteis em relação com a partilha entre unidades líticas como potenciais zonas de infiltração compartilhadas entre aqǘf́ros de duas rochas (8) as áreas de infiltração como meio de transmissão sem reservatórios strictu sensu (9) os tipos de solos (10) as ZRAs em localização e em composição, seja quando tratar-se de uma ZRA com uma única APR ou com várias APRs (11) as características petrográficas e de intemperismo em cada ZRA e, por conseguinte, de cada APR e (12) a informação sobre a geo-sensibilidade de cada ZRA e APR em função da estabilidade física e da quimiosensibilidade aos insumos e pesticidas. Com esses temas podemse agregar informações fundamentais para a construção da Arquitetura de Conhecimentos. Deriva-se daí então, a necessidade dos enunciados lógicos para o uso dessas informações. Pode-se assim apresentar algumas pré-condições para os enunciados, a título de exemplos, na seguinte seqüência:

(1) em acesso a um sistema de informação geográfico-geológico, obtém-se os mapas de localização e das áreas potenciais já agriculturadas e agriculturáveis $A P A A$ em escalas regional e local (2) o mapa de estruturas rúpteis deve ser associado ao mapa das $A P A A$ (3) as relações entre unidades líticas e $A P A A s$ são correlacionáveis para se discutir aspectos da declividade, das geoformas e características petrográficas (4) dados regionalizados sobre os atributos físicos geotécnicos das ZRAs servem para estabelecer as condições - que grau de estabilidade ou de sensibilidade mecânica (5) os dados de solos, do ponto de vista 


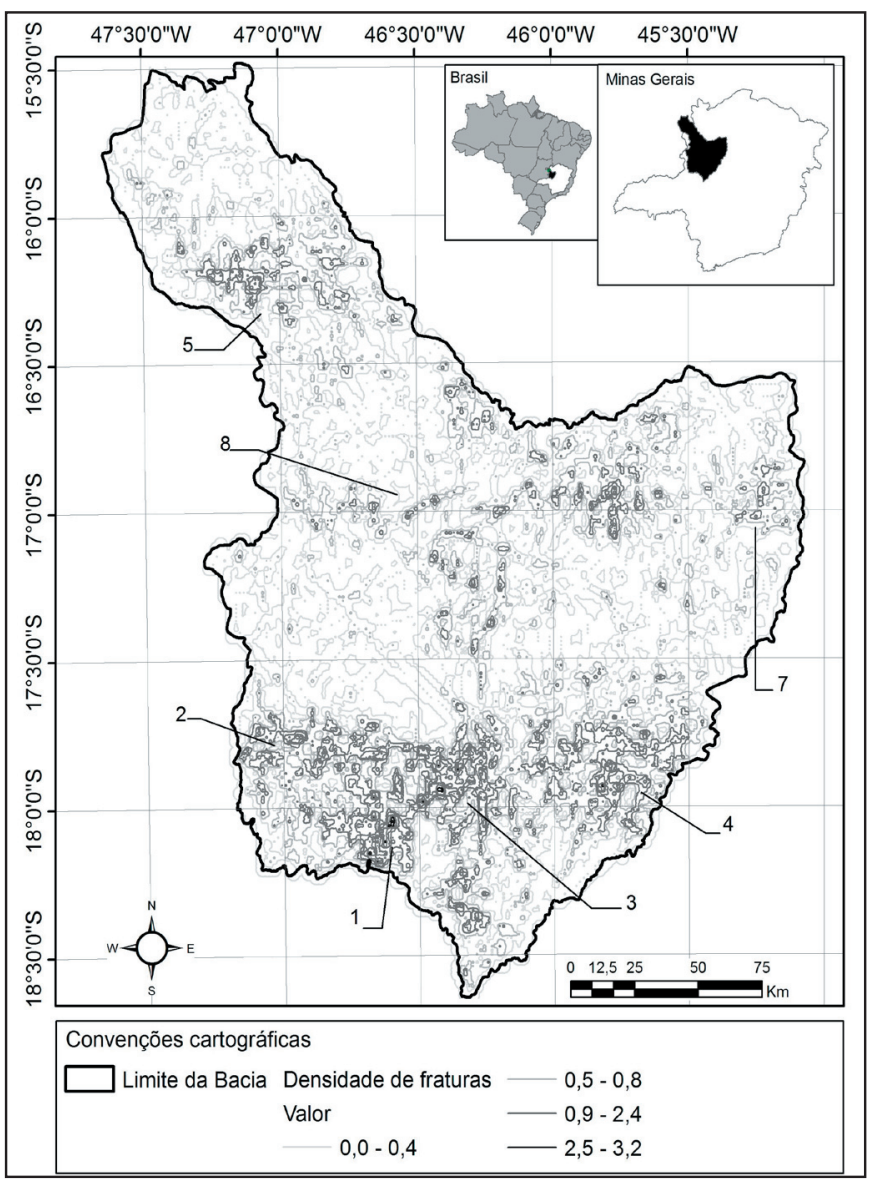

Figura 9 - Variação das densidades das fraturas tomadas pelos seus comprimentos lineares nas unidades de malha de $1.500 \mathrm{~m}$ $x 1.500 \mathrm{~m}$. Nos dois matizes mais escuros de cinza, numerados de 1 a 8, estão as áreas de maiores ocorrências de densidades de fraturas.

da infiltração da água, permitirão estabelecer aspectos da recarga que marcam a infiltração total possível na área e a infiltração real que ocorre nas condições geo-ambientais reinantes (6) a quimio-sensibilidade expressa por dados petrográficos, de intemperismo e de solos que permitirá dar graus de sensibilidade química à poluição no local.

Injunções lógicas podem então ser apresentadas, sejam como perguntas sejam como assertivas, ou como fatores limitantes, a saber: (1) a tratar-se de ZRA, pode-se pensar em projeto regional unicamente agrícola, ou florestal ou agroflorestal ou sem intervenção antrópica (2) ressalvadas condições como: - (2a) plantio nunca contínuo e total sobre a ZRA (2b) permanência ou reconstrução de corredores florestais, como unidades de conservação ecológicas ou ecológico-econômicas (2c) com as características dos solos e de aptidão dos mesmos, então, selecionar-se as condições para plantios de lavouras temporárias, lavouras permanentes, silvicultura, extrativismo e para preservação (2d) conforme o sistema de plantas escolhidas, em monocultura ou em consórcios, advêm as questões de calagem, aplicação de N P K, outros insumos como fungicidas e pesticidas que podem comprometer os solos e, eventualmente, a água em recarga, logo, então se enuncia: - se "tal plantio", então "tais necessidades", então "tais medidas de segurança", ou mesmo "não permissão para uso agrícola com insumos". Essas medidas devem ser caracterizadas no sistema, mediante acesso a mapas e ao conjunto de informações, regras enunciadas e regras de inferências geradas pelo sistema de inteligência. Cada nova

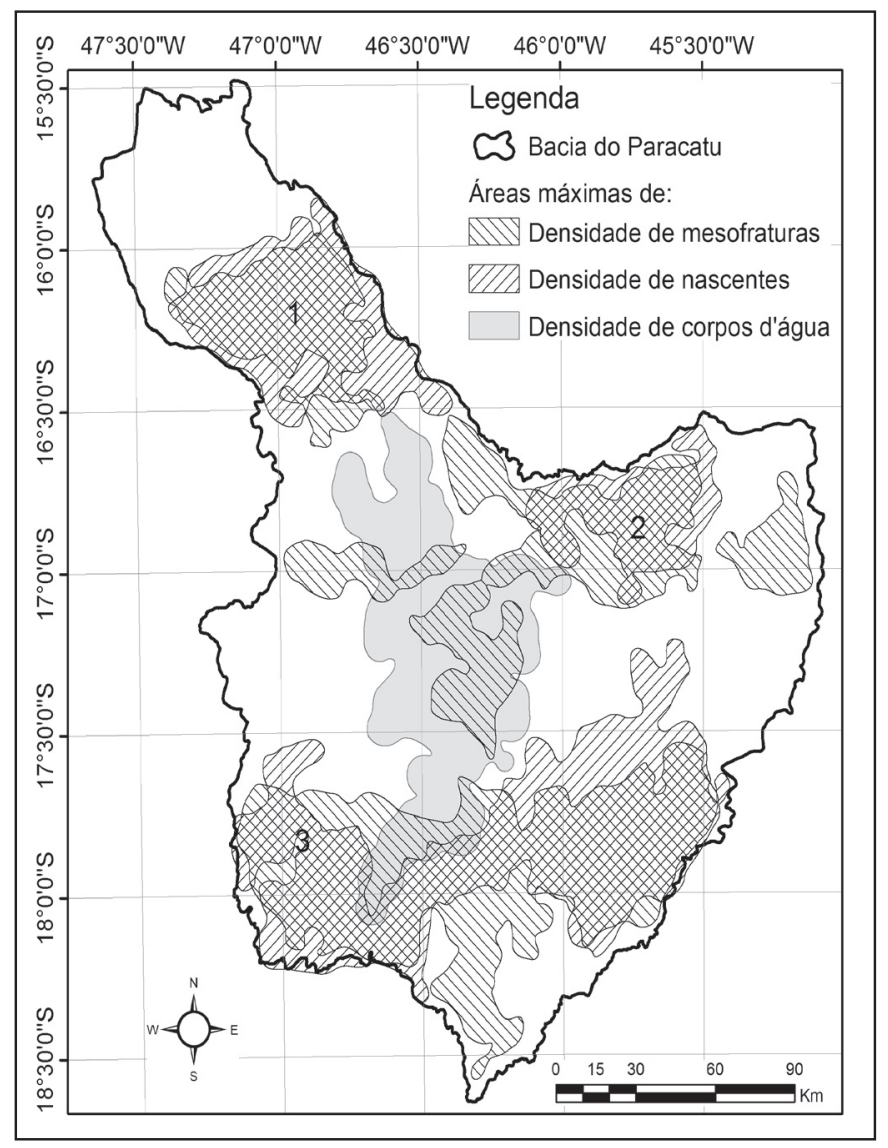

Figura 10 - Mapa integrador das relações de superposição espacial entre os máximos de densidades de mesofraturas e de nascentes; em cinza o contorno das áreas dos corpos d'água notáveis (veredas, lagoas permanentes e intermitentes, áreas de inundação). Nas áreas de números 1, 2 e 3 coincidem o maior número de estruturas rúpteis (mesofraturas) e de nascentes. Algumas zonas de recarga devem se situar fora das áreas de máximos de nascentes e de fraturas, ressalvadas algumas localizações dos aqüiferos fraturados (Grupo Canastra, Fms. Paranoá e Três Marias) e do karst fraturado (Fm. Paraopeba). A numeração indica as áreas de convergência entre máxima densidade de fraturas e mesofraturas e de máxima densidade de nascentes.

medida inferida, se logicamente verdadeira, mas não enunciada na proposição inicial da base de conhecimentos deve ser cadastrada para constituir parte da Arquitetura de Conhecimentos de medidas sobre conservação e usos dos solos, visando a segurança química (Foster, 1987) e (Foster \& Hirata, 1993). Em (3) a tipologia de solos permitirá decidir-se entre as várias culturas tanto nas condições apta, restrita e inapta, o que implicará nas condições de culturas de sequeiro, e nas condições dependentes de chuvas e nas condições dependentes de irrigação (fig. 11).

BASES DAS GEOCIÊNCIAS AGRÁRIAS E AMBIENTAIS PARA A IMPLEMENTAÇÃO DE SISTEMA INTELIGENTE Um sistema inteligente em IA necessita de pelo menos três etapas de execução: (1) a primeira envolve o reconhecimento de todos os conhecimentos entendidos como indispensáveis, não importa em qual grau, para a tomada de decisão, bem como toda a agregação desses conhecimentos em sistemas operacionalizáveis entre si (2) a agregação dos conhecimentos em um contexto lógico que obedeça a diversos conceitos epistemológicos de agregação (3) a implementação em UML (Unified 


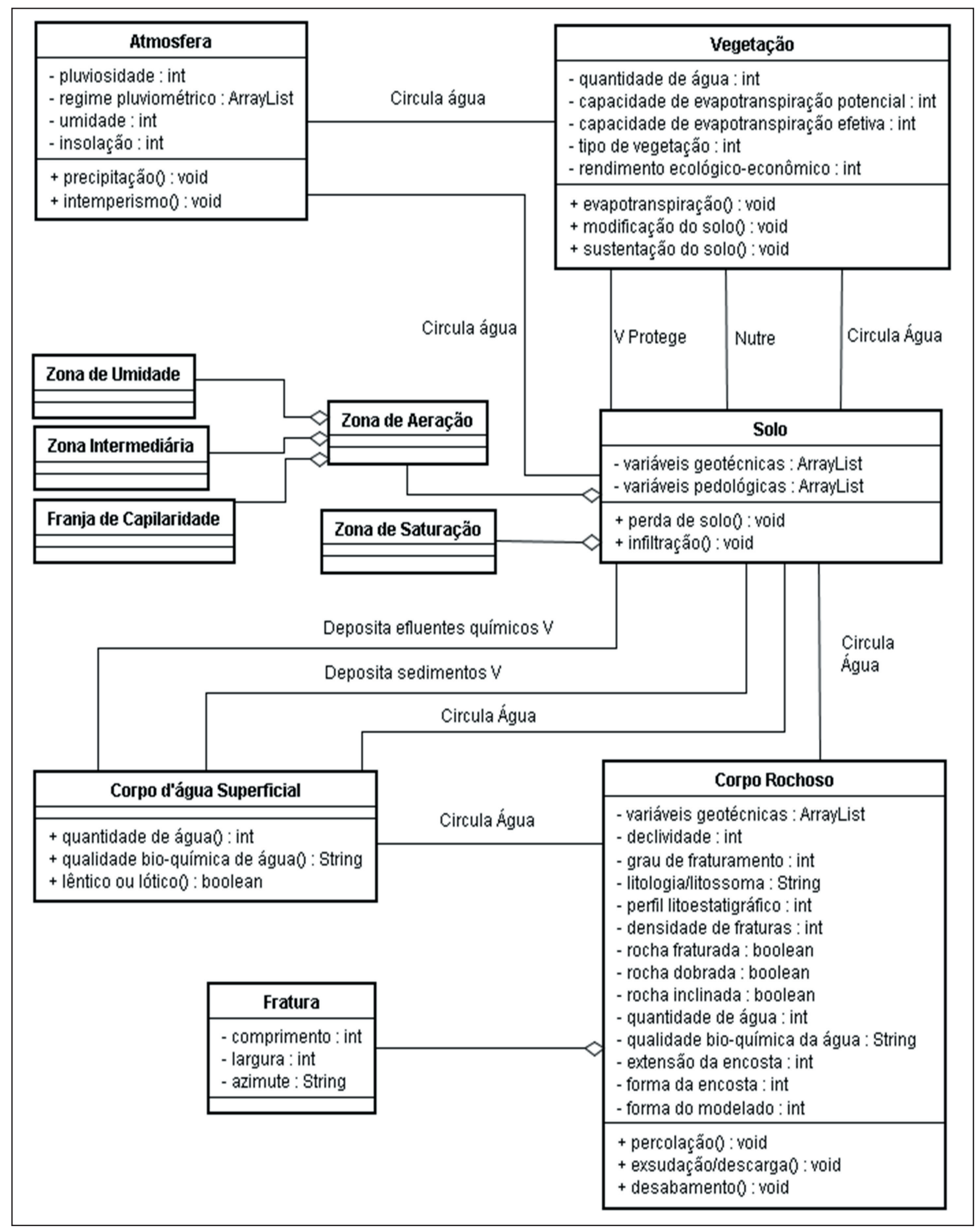

Figura 11 - Diagrama de Classes UML em nível de contexto, em que os objetos e processos são representados segundo visão delineada pelas variáveis trazidas de matrizes conhecimento geo-agro-ambientais de (algumas quebras de regras na representação se justificam para facilitar ao leitor; Os símbolos são: int-informação numérica; string-informação textual; boolean - informação lógica; void - informações variantes no tempo). 
Modeling Language) do modelo de organização lógico tanto da Arquitetura de Conhecimentos, quanto dos meandros do corpo lógico para a tomada de decisão e (4) a implementação do sistema especialista em linguagem fonte. Neste texto, agregou-se principalmente a lógica derivada das Geociências sob os aspectos da LE, GE, Pd, AS, SA e Qs. Outros aspectos são citados a título de se indicar as correlações de diversas ordens que se podem levantar ou serem inferidas conforme os diversos casos geo-ambientais e os diversos tipos e condições de uso da terra.

CONCLUSÕES Sistemas especialistas, ou de inteligência artificial, para gestão ambiental são em si um empreendimento a se desenvolver com objetivos vários, e entre eles o auxílio a decisão. $\mathrm{O}$ acesso às Geociências agrárias e ambientais ou às Geociências em geral em seus vários ramos especialistas de interesse deve ser programado sob a égide da Lógica e da Epistemologia. Essa abordagem implica em reconhecer alguns aspectos críticos para o sucesso da construção de um sistema inteligente, a saber: (1) os conceitos entre as várias ciências especialistas sobre um mesmo objeto ou processo não serem idênticos, ainda que sejam interconectos ou tenham uma interseção apreciável (2) desenhar todos os quadros de cada questão, uma a uma, quadros que devem ser desdobrados em suas unidades cognitivas lógicas, uma a uma, e as relações entre elas (3) desenhar a questão lógica, que não é uma questão intrínseca da racionalidade para consigo mesma, mas da racionalidade com as estruturas e funções dos sistemas naturais (4) desenhar a análise sistêmica que deve ser, portanto obrigatória, e por isso, deve-se reconhecer o mais precisamente possível os sistemas naturais, seus sub-sistemas bem como as relações entre eles, isto é, as relações de sistemas de sistemas, compondo assim diversos todos, e eventualmente a visão do todo de uma bacia hidrográfica. Nota-se que este conjunto de operações de (1) a (4) constitui o quadro de operações epistemológicas estritamente básicas.

Outro quadro ainda do campo epistemológico deve ser desenhado para uma Arquitetura de Conhecimentos, então já com o uso do método CommonKads para trabalhar com conceitos tais como: (1) variáveis paramétricas para qualidade da terra e efeitos esperados com atividades agrícolas e usos de insumos (2) tipos de rochas / geoformas / altitudes / densidades de fraturas / solos / aptidão de solos / parâmetros de aptidão / áreas específicas como zonas de recarga, como conteúdos cognitivos para o sistema, tendo já sido resolvidas as questões lógicas anteriormente tratadas, no que diz respeito às associações desses aspectos (3) delinear os vários objetivos de usos da terra (4) desenhar as condições das áreas especiais de uso sob diversos aspectos, tais como sensibilidade bio-ambiental e geo-ambiental, aptidão de solos e outros (5) criar desenhos de decisões sob os enfoques geotécnicos das condições de quimio-sensibilidade e sensibilidade mecânica das rochas e formações superficiais à ação antrópica (6) desenhar modelos de ação da atmosfera no âmbito dos micro-climas locais com especial ênfase aos modelos de chuvas e as interações chuvas, infiltração, evapotranspiração, escoamento superficial imediato pós-chuvas e por não menos construir (7) os Modelos de Organização de Problemas e Oportunidades (Método CommonKads) que envolvem tanto o setor Natureza quanto o setor cultural, social e econômico, o contexto geo-ambiental, o contexto de viabilidade econômica, denominado Contexto Organizacional com o estudo dos fatores internos e externos, desenhar os Aspectos de Sucesso que devem ser entendidos tanto do ponto de vista geo-ambiental quanto econômico mercadológico, e a internalização dos custos ambientais e dos ganhos imediatos e futuros no devido tratamento ambiental dos projetos agro-silvi-pastoris.

Sobre as condições de armazenamento, disponibilidade e articulação dos conhecimentos existentes, ou reconhecíveis como necessários, deve-se ainda tratar as questões referentes a: (1) a natureza do conhecimento (2) as formas de armazenamento do conhecimento (3) a disponibilidade e qualidade do conhecimento (4) a avaliabilidade do conhecimento, possivelmente dentro do conceito de Karl Popper (1994) com a noção de falseabilidade de um conhecimento, que é um aspecto fundamental do projeto científico (5) a viabilidade de execução do sistema de IA e (6) os cenários de viabilidade de planejamento da bacia hidrográfica com vários tipos e situações geo-ambientais de projetos agrícolas.

Os temas acima citados são conclusões e encaminhamentos necessários para dar prosseguimentos aos estudos com as Geociências e são algumas das conclusões da etapa até aqui esboçada. Os princípios geológicos de uso de ZRAs e APRs devem ser trabalhados como elementos cognitivos para geração de regras de inferências pelo sistema de IA como, por exemplo, o fato de quanto maior a permeabilidade de uma rocha ou de uma formação superficial em ZRA maiores os cuidados, ou mesmo a não-permissão de uso de insumos, ou então o uso da terra sob condições restritas, bem como a modelagem de atividades específicas de monitoramento dos riscos. Um sistema como esse será tão complexo quanto os sistemas naturais o são, e as interações homem-Natureza também o são. Não se espere menos, mas espere-se uma mais simples articulação dos conhecimentos como forma de lidar com homens que pensam diferentemente e não conhecem múltiplas ciências e sistemas, bem como com situações complexas do mundo real.

O que fica ainda patente como conclusão, é de que a abordagem | epistemológica / lógica / e de modelagem do conhecimento |deve ser feita de modo progressivo, envolvendo generalizações em escalas regionais próprias para os comitês de bacias, e em escalas locais próprias para as propriedades rurais. O sistema é utilizável tão logo sejam realizadas as primeiras implementações em linguagem-fonte, mas deverá em todas as situações ser desenvolvido continuadamente ao longo de muitos anos. Este texto é um estudo de caso exemplificando as questões ligadas ao uso de ZRAs e APR no sentido de se poder programar, planejar, licenciar, monitorar e mitigar essas áreas notoriamente sensíveis quando planejadas com um sistema inteligente para auxílio à decisão de gestão agrícola e geo-ambiental .

\section{Referências}

Blanchet P.H. 1956. Photogeophysics in oil and gas exploration. Annual Western Meeting, Can. Inst. Min. Metal., Vancouver, B.C.

Booch G., Rumbaugh J., Jacobson I. 1999 - The unified modeling language user guide, UML. 6th printing, Addison Wesley Publishing Company, Massachusets, EUA.

CETEC. 1981. $2^{\circ}$ Plano de desenvolvimento integrado do Noroeste Mineiro: recursos naturais. Belo Horizonte, Série de Publicações Técnicas, 2, 2v, 16 mapas.
Consórcio MAGNA/DAM/EYSER, RURALMINAS, SEAPA-MG. 1998. Plano Diretor de Recursos Hídricos da Bacia do Rio Paraca$t u$. PLANPAR. Relatório Síntese. Minas Gerais, 135p.

Endo I. 2006. Geologia Estrutural Regional do Paracatu. Ouro Preto, Fundação CETEC (Memória Técnica) / UFOP-EM-DEGEO. Nota Técnica NT-CRHA 59/2006. 19p. Disponível em: www.crha.cetec. $b r$.

Foster S. 1987. Fundamental concepts in aquifer vulnerability pollution 
risk and protection strategy. In: Proc. Intern. Conf. "Vulnerability of Soil and Groundwater to Pollutants". Noodwijk, Nederlands.

Foster S. \& Hirata R. 1993. Determinação do risco de contaminação das águas subterrâneas. $2^{\mathrm{a}}$ edição, São Paulo, Instituto Geológico, Boletim 10, $92 \mathrm{p}$.

Laurière J-L. 1990 . Problem Solving and Artificial Intelligence. Prentice-Hall, Inc. Upper Saddle River, NJ, USA

Martins Jr.P.P. 1998. Fundamentos conceituais para o desenvolvimento e a prática das geociências agrárias e ambientais. A Terra em Revista, 4:10-15.

Martins Jr., P.P. 2002. Epistemologia fundamental. Um estudo introdutório sobre a estrutura do conhecimento e a aplicação prática da epistemologia na pesquisa Científica. Belo Horizonte: Fundação CETEC-Memória Técnica - Relatório Final. 169p.

Martins Jr., P.P. 2003. As proposições Metodológicas do Projeto CRHA. Belo Horizonte, CETEC (Memória Técnica)/UFOP. Projeto convênio MCT/FINEP 2.132/2002, Nota Técnica NT-CRHA-01. 39p. Disponível em: www.crha.cetec.br.

Martins Jr., P.P., Pereira M.A.S., Novaes L.A.d'A., Vasconcelos, V.V. 2005 A. Zonas de Recarga de Aqüiferos - Questões Estruturais e Geo-ambientais. Belo Horizonte, Fundação CETEC (Memória Técnica) / UFOP-EM-DEGEO. Nota Técnica NT-CRHA 52, 19p. Disponível em: www.crha.cetec.br.

Martins Jr. P.P., Pereira M.A.S., Novaes L.A.d'A., Vasconcelos V.V. 2005 B. Zonas de Recarga de Aqüiferos - Reservatórios - Nascentes - Questões Geo-Ambientais. Belo Horizonte, Fundação CETEC (Memória Técnica) / UFOP-EM-DEGEO, Nota Técnica
NT-CRHA 54. Disponível em: www.crha.cetec.br.

Mollard J.D. 1957. Aerial mosaics reveal fracture patterns on surface in Southern Saskatchewan and Manitoba. Oil in Canada, 9:26-50.

Pooper, K. 1994. Toute Vie est Résolution des Problèmes. Questions Autour de la Connaissance de la Nature. Actes Sud., Paris, 168p.

Projeto CRHA. 2006. Conservação de recurso hídrico no âmbito da gestão ambiental e agrícola de Bacia Hidrográfica. Projeto convênio MCT / FINEP / CETEC-UFOP IGAM 2.132/2002. (2003-2006). Relatório Final Tomos I a III. Disponível em: http://www.crha.cetec.br/crha/index.htm.

Schreiber G., Akkermans H., Anjewierden A., De Hoog R., Shadbolt N., Van De Velde W., Wielinga B. 2000. Knowledge Engineering and Management. The CommonKads Methodology. The MIT Press, London, $447 \mathrm{p}$.

Silva A.B., Martins Junior P.P., Tonini Junior G., Tannus M.B., Garcia P.C., Araújo A. G., Cruz W.B., Bertachini A.C., Garcia E.P., Rosière C.A. 1989. Desenvolvimento de modelo estatístico de interpretação de dados geológicos morfo-estruturais aplicados à hidrogeologia de rochas fraturadas. Belo Horizonte. Proj. PADCT / CETEC. Rel. Final. 97 p. anexos.

USAF-AST10 1964. Aerofotos Escala de 1:60.000. Blanchet, P.H. 1956. Photogeophysics in Oil and Gas Exploration. Annual Western Meeting, Can. Inst. Min. Metal., Vancouver, B.C..

Manuscrito AE024

Aprovado em 6 de dezembro de 2006 